\title{
EFEITO DA MISTURA E24 COMPARADO À GASOLINA PURA NA ESPESSURA DA FASE LIVRE EM POÇOS DE MONITORAMENTO
}

\author{
GASOHOL (E24) EFFECTS ON THE FREE PHASE THICKNESS WITHIN MONITORING WELLS \\ COMPARED TO PURE GASOLINE EFFECTS
}

\author{
Everton de Oliveira ${ }^{1}$ e Maria Anísia de Castro Pereira ${ }^{2}$
}

\begin{abstract}
Recebido em: 14/10/2005; aceito em: 21/03/2006
RESUMO O cálculo de recuperação de gasolina no aqüífero está baseado na relação entre as espessuras do combustível no poço de monitoramento e no meio poroso. O etanol como aditivo a gasolina afeta esta disposição na franja capilar. Neste artigo está descrito o efeito do E24 (76\% gasolina, 24\% etanol por volume) em comparação à gasolina pura na franja capilar e na correspondência de espessuras de fase livre no aqüífero e poço de monitoramento. Para esta demonstração foram utilizadas duas colunas de acrílico preenchidas por microesferas de vidro, que produziu as diferenças visuais e associações em situações de campo. Os resultados indicam que a elevação da franja capilar foi menor no E24 quando comparado à gasolina. Fato associado ao efeito cossolvente do etanol sobre a tensão interfacial; a formação de fase livre no E24 no poço de monitoramento foi anterior à da gasolina; o E24 alcançou o limite físico do microcosmo em tempo anterior ao da gasolina; a migração do E24 no poço ocorreu em menor tempo, indicando que vazamentos em subsuperfície podem ser detectados mais rápido se os poços de monitoramento forem instalados nos limites do sítio; a relação de espessuras de fase livre no poço e no aqüífero foi de 4 vezes para E24 e de 2,6 vezes para gasolina. Isto indica que para projetos de remediação de E24 baseado na relação de características da gasolina pode superestimar o volume de produto recuperado (extraído do aquiífero) em $20 \%$.
\end{abstract}

Palavras Chave: gasolina, etanol, fase livre, poço de monitoramento, tensão interfacial

\begin{abstract}
Free-phase gasoline remedial schemes are based on the gasoline's thickness layer measured on monitoring wells. The relationship of the thickness within the well and in the aquifer depends on the elevation of the water table. Ethanol presents in gasoline affects the elevation of the capillary fringe. This paper presents the effects of E24 (76\% gasoline, $24 \%$ ethanol by volume) compared to pure gasoline on the elevation of the capillary fringe and the correspondent thickness of free phase within the monitoring well and in the aquifer. Two plexiglass columns filled with glass beads were used to perform visualization experiments and to produce an appropriate relationship that can be applied to the field situations. The results indicated that the elevation of the capillary fringe was lower for E24 compared to gasoline, as expected from the ethanol cosolvent effects on the interfacial tension; E24 established a free phase layer faster than that of the gasoline; E24 spill would reach a microcosm edge faster compared to that of gasoline; the migration of E24 to the well was faster than that of the gasoline, indicating that a subsurface spill could be detected earlier by monitoring wells installed within the gas station limits; the relationship of the thickness of the free phase product within the well to thickness in the aquifer for E24 was 4 and for gasoline was 2.6. This indicates that a remedial scheme for E24 based on gasoline relationship would overestimate the volume of product to be extracted from the aquifer by $20 \%$.
\end{abstract}

Keywords: gasoline, ethanol, free phase, monitoring well, interfacial tension

\section{INTRODUÇÃO}

$\mathrm{O}$ etanol como combustível adicionado à gasolina é uma prática comum em muitos países a exemplo do Canadá e EUA, sendo que neste vem sendo aprimorado o estudo para substituição pelo MTBE. No Brasil, este álcool é utilizado nas proporções de 22 a $25 \%$ há mais de 20 anos. O etanol foi uma alternativa ao uso de combustíveis importados e minimização de emissão de compostos poluentes para o ar advindo da queima de combustível fóssil. Os efeitos da relação entre os fluidos da mistura ternária gasolina, água e etanol formam a base do conhecimento do comportamento de fluxo do vazamento de E24 ( $76 \%$ de gasolina e $24 \%$ de etanol, em volume) em subsuperfície.

Como propriedade físico-química do etanol, o efeito cossolvente no E24 na franja capilar induz a uma redução da espessura de fase livre e aumento de solubilidade tanto em gasolina quanto em água.

O etanol é solúvel na gasolina e em água, isto é chamado de cossolvência, cujo princípio básico é o efeito do E24 na franja capilar com a redução da espessura de fase livre. de Oliveira (1997) mostra que ao entrar em contato com água e gasolina, o etanol particiona-se preferencialmente para água, e, uma vez na água o volume e densidade mudam na mistura. $O$ diagrama ternário em de Oliveira (1997), figura 1, mostra esta tendência do etanol. Quando em contato com água no topo da franja capilar, parte do etanol contido no E24 particionará para água, resultando na redução da tensão interfacial entre as duas fases. O comportamento inicial entre o E24 como LNAPL (Light non-aquous phase liquid) e a água mudará as relações da fase gasolina e fase água. A fase gasolina será re-definida como a mistura

\footnotetext{
${ }^{1}$ Hidroplan Hidrogeologia e Planejamento Ambiental Ltda (everton@ hidroplan.com.br)

${ }^{2}$ Mestre em ciências (área de Hidrogeologia) pela Universidade de São Paulo - USP (anisiadecastro@yahoo.com.br)
} 
de gasolina, etanol e água e a fase água será a mistura de água, etanol e compostos solúveis de gasolina dissolvidos. Além disso, na partição do etanol para fase água a tensão interfacial entre as duas fases reduzirá.

Este estudo apresenta os efeitos do E24 comparado com gasolina pura na elevação da franja capilar e espessura correspondente da fase livre no poço de monitoramento e no aqüífero. A fim de visualizar-se a razão entre a espessura real e aparente de E24, duas colunas preenchidas com microesferas de vidro simulam situação de campo em um vazamento de gasolina em aquífero livre.

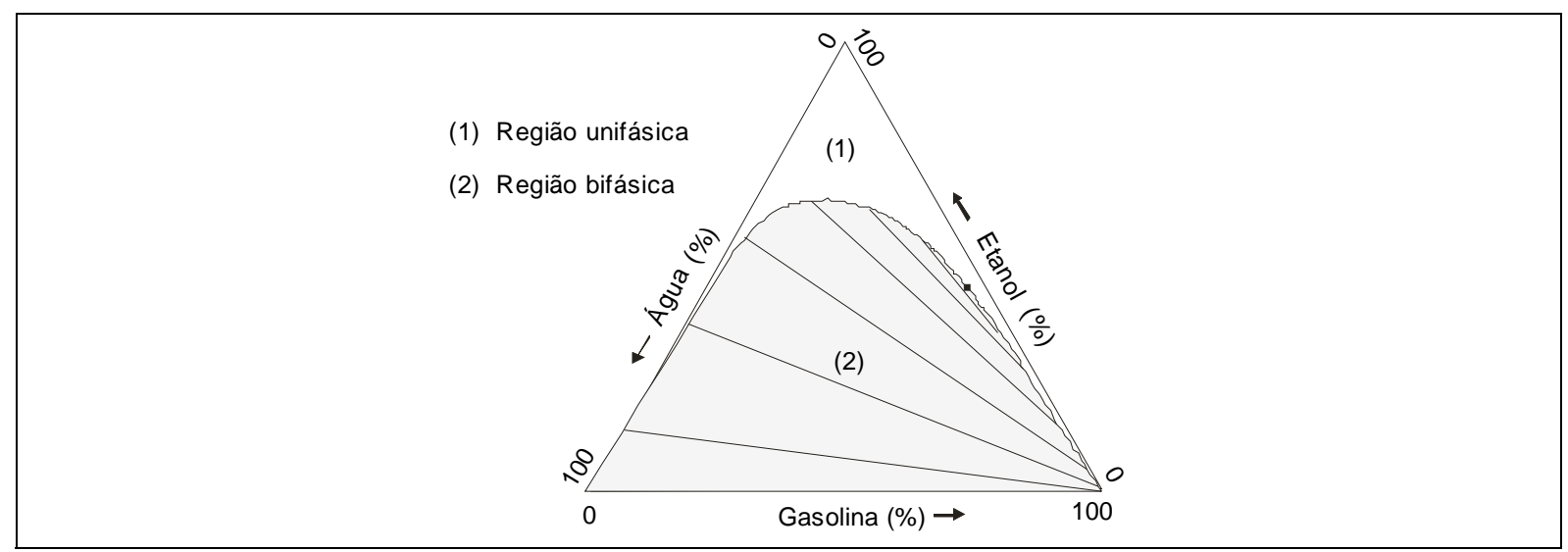

Figura 1- Diagrama ternário (OLIVEIRA, 1997)

Figure 1- Ternary Diagram (OLIVEIRA, 1997)

\section{OBJETIVOS}

Este estudo tem como objetivo a comparação dos efeitos da E24 na elevação da franja capilar em comparação à gasolina pura; observação do espalhamento do E24 em comparação à gasolina pura; comparação entre a espessura da fase livre no poço de monitoramento com a espessura no aquiífero da E24 e gasolina.

\section{PROCEDIMENTOS EXPERIMENTAIS}

Os comportamentos da gasolina pura e E24 no topo da franja capilar e em poços de monitoramento foram simulados, em laboratório, com a construção de um microcosmo estático. A sequiência da montagem inicia com duas colunas cilíndricas de $100 \mathrm{~cm}$ de altura e $23 \mathrm{~cm}$ de diâmetro interno, em material acrílico. As bases das colunas foram vedadas com duas placas de acrílico de $15 \mathrm{~cm}$ de raio e dimensões $35 \mathrm{x}$ $35 \mathrm{~cm}$. Uma flange de PVC de 1" foi adaptada à extremidade lateral inferior e conectada a tubos de polietileno de $6,36 \mathrm{~mm}$ (1/4"). A extremidade superior foi vedada com placas acrílicas perfuradas na região central com orifício de $5 \mathrm{~mm}$ para permitir a injeção de gasolina ou E24.

Uma segunda peça cilíndrica com dimensões de $100 \mathrm{~cm}$ de comprimento e $3 \mathrm{~cm}$ de diâmetro em PVC cristal transparente foi seccionada longitudinalmente, a fim de se portar como poço de monitoramento. As paredes deste tubo foram submetidas a cortes paralelos de $8 \mathrm{~mm}$ de comprimento e $1 \mathrm{~mm}$ de abertura ao longo do mesmo. A disposição das ranhuras permitirá a migração do combustível em fase livre para o interior do poço (Figura 2). A metade do tubo foi fixada à parede da coluna com o auxílio de varetas plásticas de $21,5 \mathrm{~cm}$ de comprimento, que equivale a subtração do diâmetro da coluna à seção do tubo de cristal.

O espaço entre a coluna e o cilindro foi então preenchido com microesferas de vidro de $850 \mu \mathrm{m}$ de diâmetro (granulometria de areia grossa), que foram homogeneizadas em etapa anterior. As hastes plásticas foram removidas à medida que as microesferas de vidro eram sedimentadas até o alcance do topo da coluna.

O diâmetro de cada peça que compõe o experimento - microesferas de vidro, flange, colunas e tubos - foram escolhidos baseados na experiência de Schiegg e McBride (1987) e Lal et al (1970), em que a razão entre os dois cilindros (coluna e poço de monitoramento) foi projetada para evitar o efeito parede. O mecanismo para injeção de gasolina ou E24 se deu por um tubo de vidro de $1,5 \mathrm{~cm}$ de diâmetro inserido no centro da porção superior das colunas. A base deste conduto foi mantida próxima ao topo da projeção da franja capilar. Em primeira etapa, as colunas foram gradualmente preenchidas, a partir da base, com água deionizada e deaerada em uma vazão de $50 \mathrm{~mL} / \mathrm{min}$ até serem completamente saturadas. O segundo passo foi o rebaixamento do nível de água até que este se mantivesse a $53 \mathrm{~cm}$ em ambas colunas. 


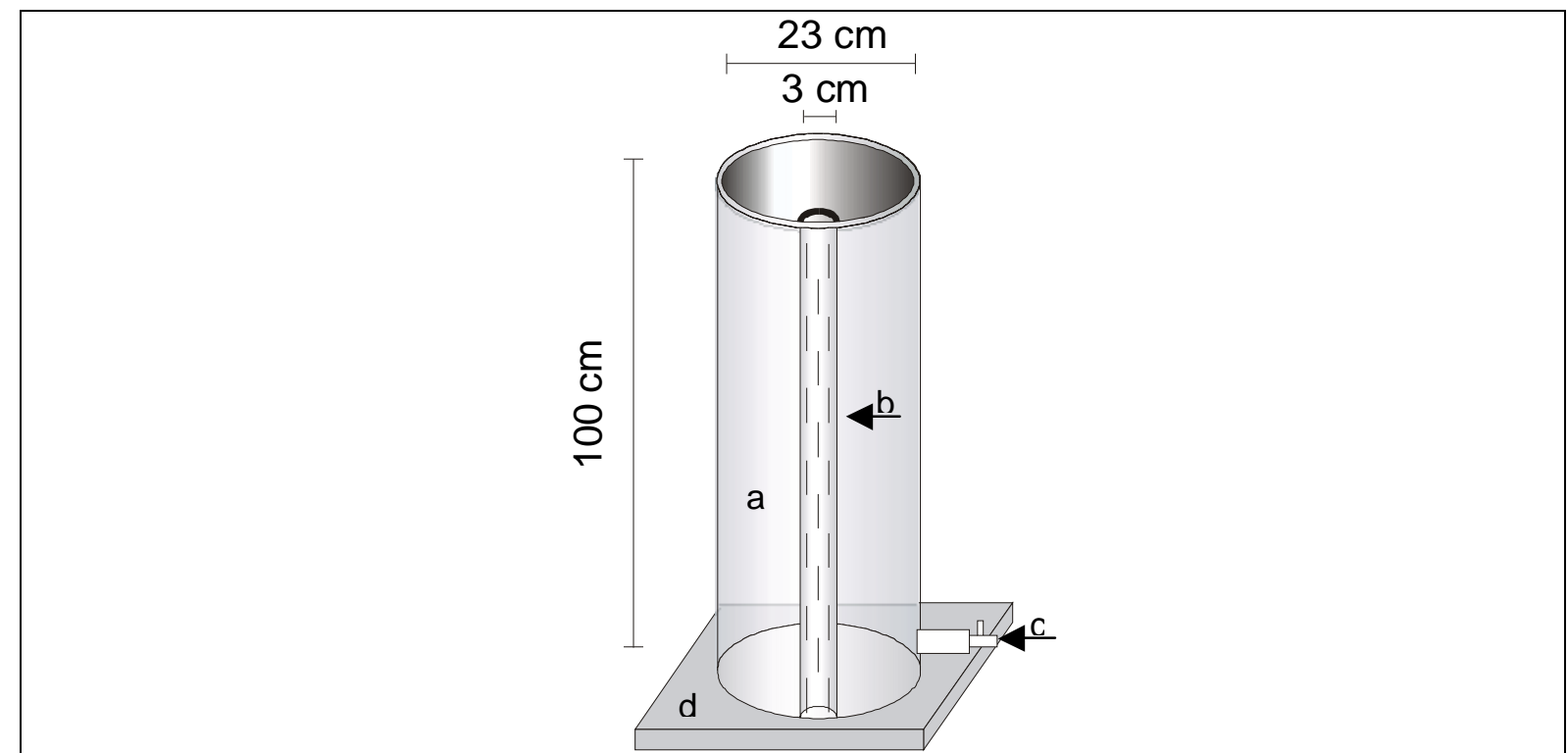

Figura 2- Detalhes do experimento: a) coluna acrílica; b) tubo PVC cristal ranhurado; c) flange; d) base acrílica Figure 2- Experiment: a) plexiglass column; b) screened PVC tube; c) flange; d) plexiglass platform

De acordo com Polubarinova-Kochina (1952, 1962) in Bear (1979), a elevação da franja capilar pode ser calculada por :

$$
h_{c c}=\frac{0,45}{d_{10}} \frac{1-n}{n}
$$

Onde, $h_{c c}$ é a elevação da franja capilar a partir do nível de água, $d_{10}$ é o diâmetro efetivo dos grãos e $n$ porosidade efetiva do meio poroso. Para $\mathrm{n}=30 \%$ e $\mathrm{d}_{10}=0,085 \mathrm{~cm}$, desta equação resultou $\mathrm{h}_{\mathrm{cc}}=12,2 \mathrm{~cm}$.

Um valor similar foi obtido no ensaio de bancada.
Baseado neste cálculo foi possível garantir que medidas como nível de água, elevação da franja capilar e espessura da fase livre fossem comportadas na coluna e evitou-se o excesso de gasolina, que porventura superá-se o comprimento do poço de monitoramento ou extrapole a base das colunas.

As elevações do nível de água e da franja capilar foram visualizadas através do poço de monitoramento e das microesferas de vidro do meio poroso. A homogeneidade do meio foi comprovada, visualmente, pela uniformidade da frente molhante e estabilidade da franja capilar (Figura 3).

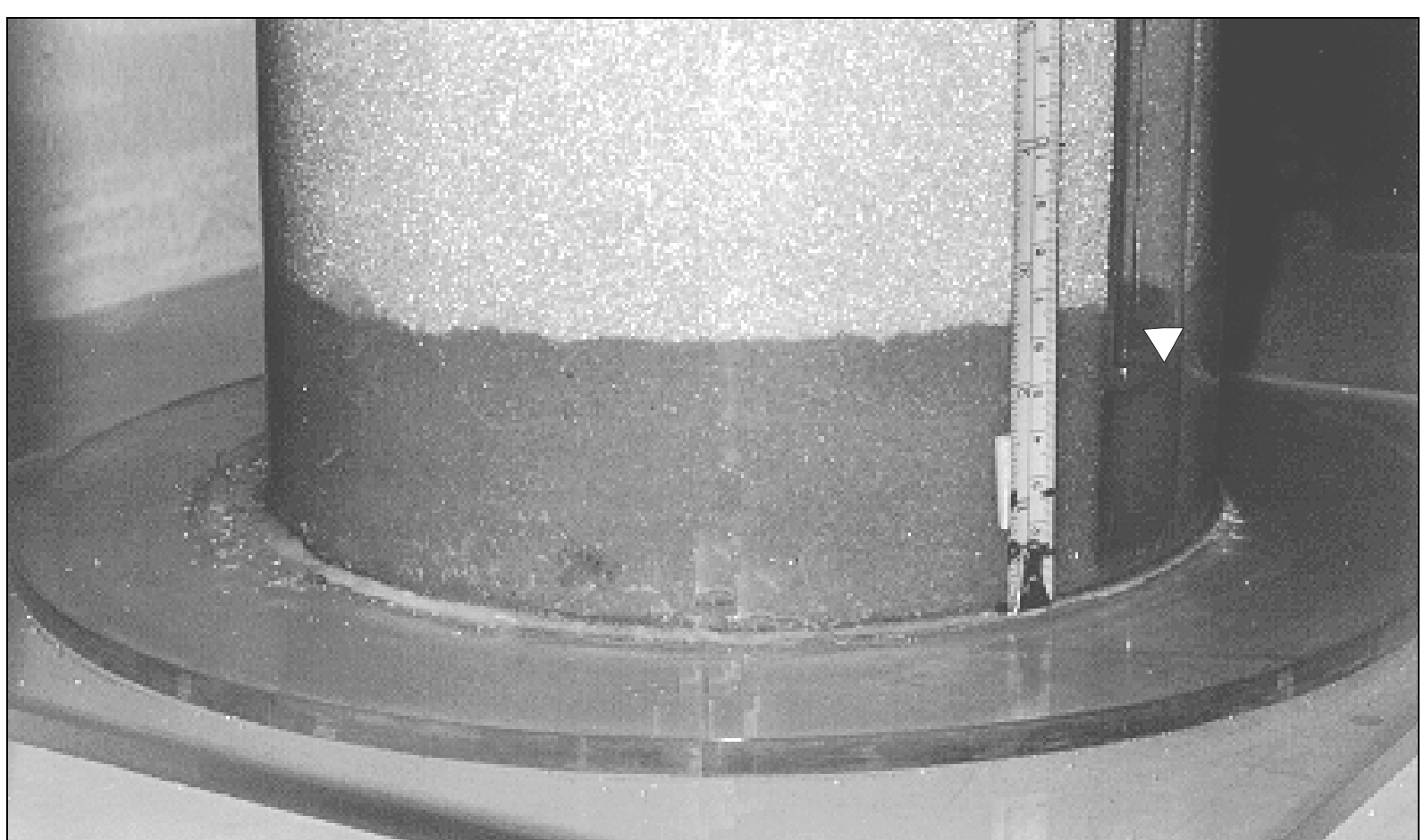

Figura 3- Frente molhante uniforme

Figure 3- uniform wetting front 
A tabela 1 mostra os resultados das medidas de elevação da franja capilar nas colunas A e B, que comportaram, respectivamente, gasolina pura e E24

Tabela 1- Posição final do nível de água e franja capilar

Table 1- Final position of the water table and top of the capillary fringe

\begin{tabular}{c|c|c}
\hline & $\begin{array}{c}\text { Elevação de nível } \\
\text { de água* }(\mathbf{c m})\end{array}$ & $\begin{array}{c}\text { Elevação da franja } \\
\text { capilar* }(\mathbf{c m})\end{array}$ \\
\hline $\begin{array}{c}\text { Coluna A } \\
\text { (gasolina pura) }\end{array}$ & 58,6 & 64,4 \\
\hline $\begin{array}{c}\text { Coluna B } \\
\text { (E24) }\end{array}$ & 62,3 & 67,8 \\
\hline
\end{tabular}

\section{INJEÇÃO DE GASOLINA E E24}

Assumindo-se o objetivo deste estudo pela observação de variações físicas relacionadas à fase separada, a tabela 2 apresenta as proporções e densidades da gasolina pura e E24 utilizadas no experimento.

Tabela 2- Propriedades dos combustíveis Table 2- Fuel parameters

\begin{tabular}{c|c|c|c}
\hline & $\begin{array}{c}\text { Densidade } \\
\left(\mathbf{g} / \mathbf{c m}^{\mathbf{3}}\right)\end{array}$ & $\begin{array}{c}\text { Gasolina } \\
(\mathbf{\%})\end{array}$ & $\begin{array}{c}\text { Etanol } \\
(\mathbf{\%})\end{array}$ \\
\hline Gasolina pura & 0,7365 & 100 & 0 \\
\hline E24 & 0,7241 & 76 & 24 \\
\hline
\end{tabular}

Fonte: Cia. de Petróleo Ipiranga

Para que houvesse contraste de cor entre a matriz sólida e o efeito do espalhamento dos combustíveis o corante ditizona vermelha foi misturado à gasolina pura e ao E24. Como resultado, a gasolina pura adquiriu a cor vermelha e o E24 laranja (cinza escuro e claro, respectivamente neste artigo).

Os dois combustíveis foram dispostos no topo da franja capilar através de um tubo de vidro ajustado verticalmente ao nível da elevação da franja capilar no equilíbrio. O volume de $610 \mathrm{~mL}$ foi a quantidade de ambos combustíveis acumulados nas colunas após cinco horas de liberação das gasolinas no aqüífero artificial. $\mathrm{O}$ experimento foi monitorado durante 60 dias após o estabelecimento do equilíbrio. A figura 4 mostra a configuração das colunas.

\section{RESULTADOS E DISCUSSÃO}

Após a simulação de vazamentos simultâneos em ambas colunas e utilizando as mesmas cargas de elevação, observou-se que o fluxo da gasolina pura foi mais lento que o respectivo para o E24; o E24 desenvolveu uma menor espessura de fase livre que a gasolina pura; a primeira fase livre a formar-se ocorreu na coluna do E24 e continuou mais rápida até todo o volume $(61 \mathrm{~mL})$ ter sido liberado no meio. $\mathrm{O}$ fato da viscosidade do E24 ser inferior ao da gasolina pura explica parcialmente este resultado. Migrando com menor viscosidade, a partição do etanol para fase água presente na zona não saturada reduz a tensão interfacial e permite a invasão dos poros pelo combustível E24, que não poderiam ser preenchidos pela gasolina pura. Correlacionando-se a uma situação real de meio homogêneo infere-se que durante um derramamento de E24, este teria maior mobilidade que a gasolina pura devido a sua baixa viscosidade acarretando em alcances de maiores distâncias comparadas à gasolina pura. Ainda, a redução da tensão interfacial permite a entrada por poros anteriormente preenchidos por água.

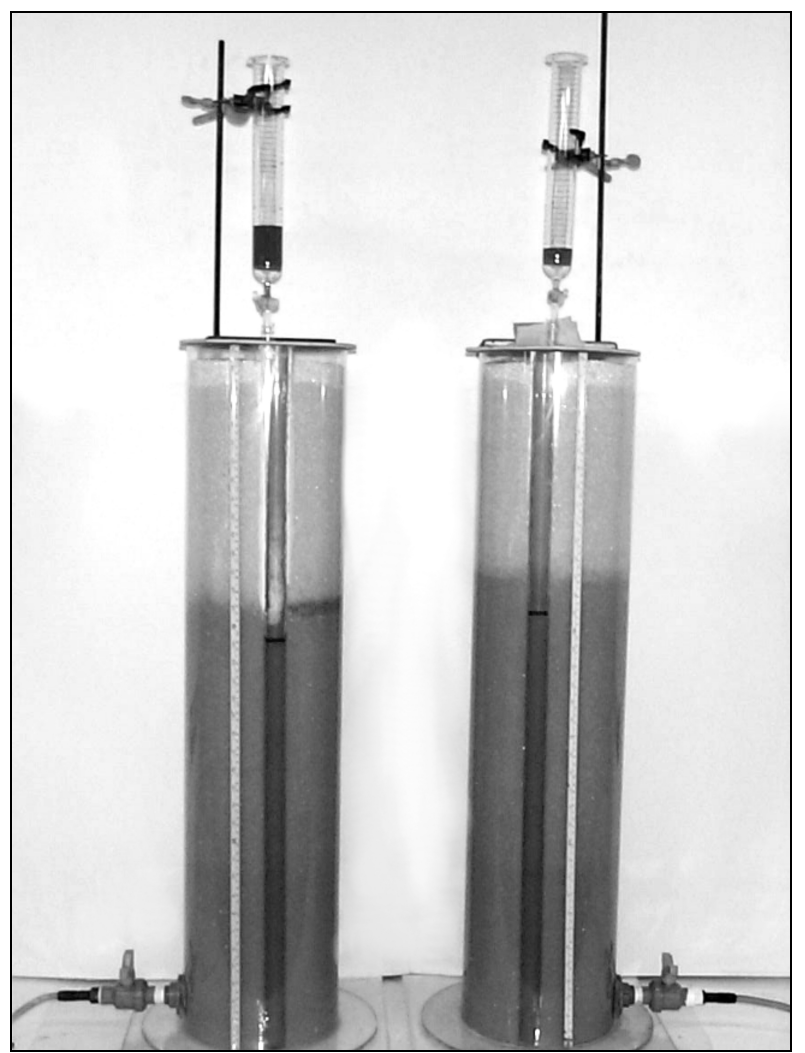

Figura 4- Sistemas de colunas completo: esquerda E24 e direita gasolina pura

Figure 4-Complete set of columns: E24 on the left and pure gasoline on the right

Ambos combustíveis não penetraram os poços de monitoramento imediatamente após a formação de fase livre no meio poroso / franja capilar (Figura 5). Abdul et al (1989) e Marineli and Durnford (1996) explicam este fenômeno com base nas diferenças de pressão e volume do hidrocarboneto vazado para o solo. A fase livre se acumulou no topo da franja capilar, onde a água e ar permaneciam em pressão negativa. No estágio inicial de acúmulo, as gasolinas estão à 
baixa pressão de carga, insuficiente para iniciar a migração para o poço de monitoramento por variação de potencial. A saber, LNAPL (Light Non Aquous Phase Liquids) sobre a franja capilar à pressão negativa não flui do meio poroso para o poço. A região do nível de água no poço de monitoramento está à pressão zero.

Segundo Adamski et al (2005) a baixa saturação predispõe o LNAPL ao solo, em que uma pressão capilar maior é necessária para deslocar a água da matriz porosa.
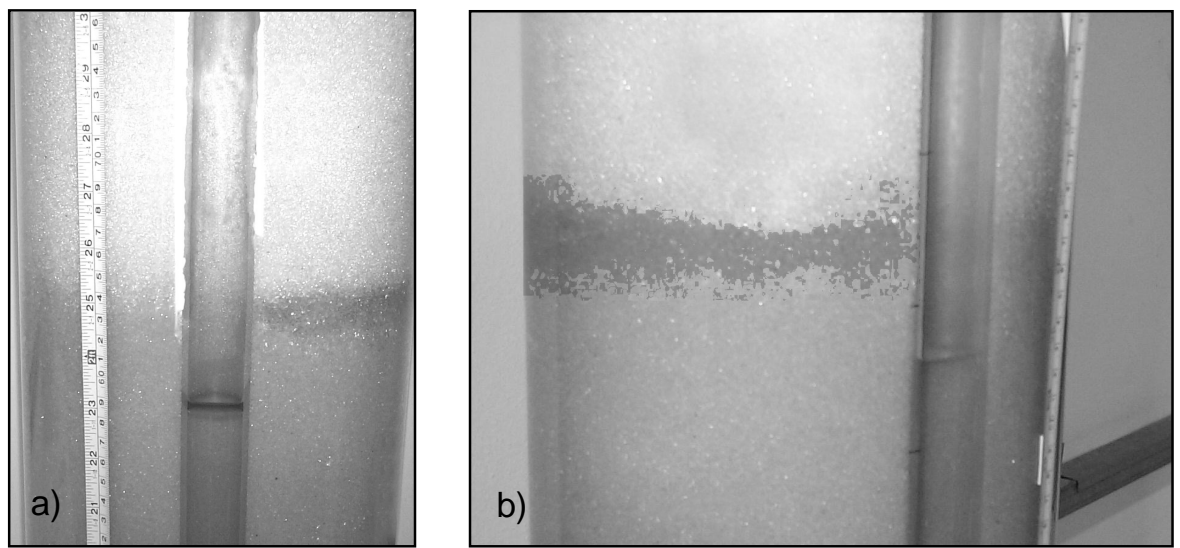

Figura 5- Formação inicial de fase livre, a) gasolina pura b) E24

Figure 5- Initial formation of free phase: a) pure gasoline b) E24

No início da migração dos combustíveis para os respectivos poços de monitoramento e finalizado o vazamento, o E24 continuou a fluir lentamente para o poço até $\mathrm{o} 38^{\circ}$ dia de acompanhamento, enquanto para o mesmo cenário a gasolina pura havia estagnado no $11^{\circ}$ dia. Após este e até o final do período de monitoramento (60 dias), o fluxo na direção do poço de monitoramento permaneceu estagnado a olho nu. A diferença de comportamento da estabilidade é atribuída à presença de etanol.

Como o álcool particiona, por difusão, lentamente para a fase água na franja capilar, a tensão interfacial modifica-se gradualmente. Consequientemente, parte do E24 pode invadir os poros que estavam bloqueados pela presença de água (na forma de filme, anéis pendulares ou anéis de água). Com este fato infere-se que uma massa menor de E24 permanece no aqüífero como fase livre quando comparado com gasolina pura.

McDowell et al (2003) estudaram os efeitos da atuação do etanol em ambiente precedido de contaminação por gasolina dispersa em zona não saturada. Como resultado obtiveram uma redução da área anteriormente ocupada pela gasolina (residual/adsorvida) na zona não saturada e a formação de uma fase dissolvida, além da mobilização comprovada de compostos da gasolina para a água subterrânea. Resultado: uma menor área ocupada pela gasolina pura na zona não saturada; maior saturação dissolvida, e; alteração do fluxo dos compostos da gasolina para água subterrânea.
McDowell et al (2003) relatam um caso real em que uma área que apresentava espessuras máximas de LNAPL (óleo diesel e óleo lubrificante) de $0,058 \mathrm{~m}$ a $0,116 \mathrm{~m}$ em poços de monitoramento no período de dois anos, após uma nova contaminação, desta vez por etanol, passou a apresentar espessuras de 0,5 a $0,8 \mathrm{~m}$ nos novos poços de monitoramento instalados para avaliar o novo cenário. Três meses após o vazamento a concentração de etanol era de $18.000 \mathrm{mg} / \mathrm{L}, 2$ anos e 5 meses após o vazamento a concentração era de $20 \mu \mathrm{g} / \mathrm{L}$. No entanto, houve um aumento de 15 vezes na concentração de benzeno (102 para $1.500 \mu \mathrm{g} / \mathrm{L})$ cinco meses após o vazamento, atribuído ao efeito de cossolvência e diminuição do grau de biodegradação do benzeno.

Em um ensaio simulando as condições do vazamento citado, McDowell et al (2003) notaram uma modificação da molhabilidade entre os fluidos devido as tensões superficiais e interfaciais. Em que a diminuição da tensão interfacial gasolina e etanol permitiu uma maior mobilidade da gasolina (fase livre) em poros menores, consequientemente aumentando a permeabilidade efetiva e causando um incremento ao transporte desta.

Para o atual experimento, após o equilíbrio ser restabelecido, a relação de espessuras do produto em fase livre no poço de monitoramento para a espessura deste no aqǘf́ero foi de 4 vezes para E24 e para gasolina pura de 2,6 vezes. A figura 6 mostra a configuração final da gasolina pura e E24 no meio poroso, em que as diferenças 
de espessuras são visualizadas em ambas colunas. Mustafa e Liao (2000) atribuíram a pressão capilar e concluíram que a maior espessura do LNAPL no poço de monitoramento que a Formação é causado pelo efeito da pressão capilar, ausente no poço, na interface água/LNAPL da Formação sob condições de equilíbrio. Quanto maior a espessura de LNAPL na Formação maior será a espessura no poço de monitoramento.

Quanto aos parâmetros que influenciam esta razão Mustafa e Liao (2000) exemplificam com a permeabilidade, em que a espessura do LNAPL diminui com o aumento desta. Isto implica que em casos específicos a espessura de LNAPL, quando a interface água/LNAPL alcançar altura máxima, pode representar a espessura de LNAPL na Formação.

Cain et al (2000) utilizando o etanol como traçador não reativo notou uma perda de massa do álcool em experimento similar quanto ao uso de células completamente fechadas e sem percepção de vazamento. Eles associaram a biodegradação, no entanto utilizaram matriz natural.

Pastrovish et al (1979) sugeriram que a medida de espessura de hidrocarbonetos nos poços de monitoramento seja de aproximadamente quatro vezes a verdadeira espessura na Formação. Esta razão foi derivada de uma estimativa simplificada de balanço de forças. Dakin et al (1992) aplicaram este princípio com vazamento de xileno e chegou ao resultado similar. A conclusão de de Pastrovish et al (1979) e Abdul et al (1989) combina com as medidas de espessura de E24. No entanto, para a gasolina pura não houve correlação com $o$ mesmo fator.

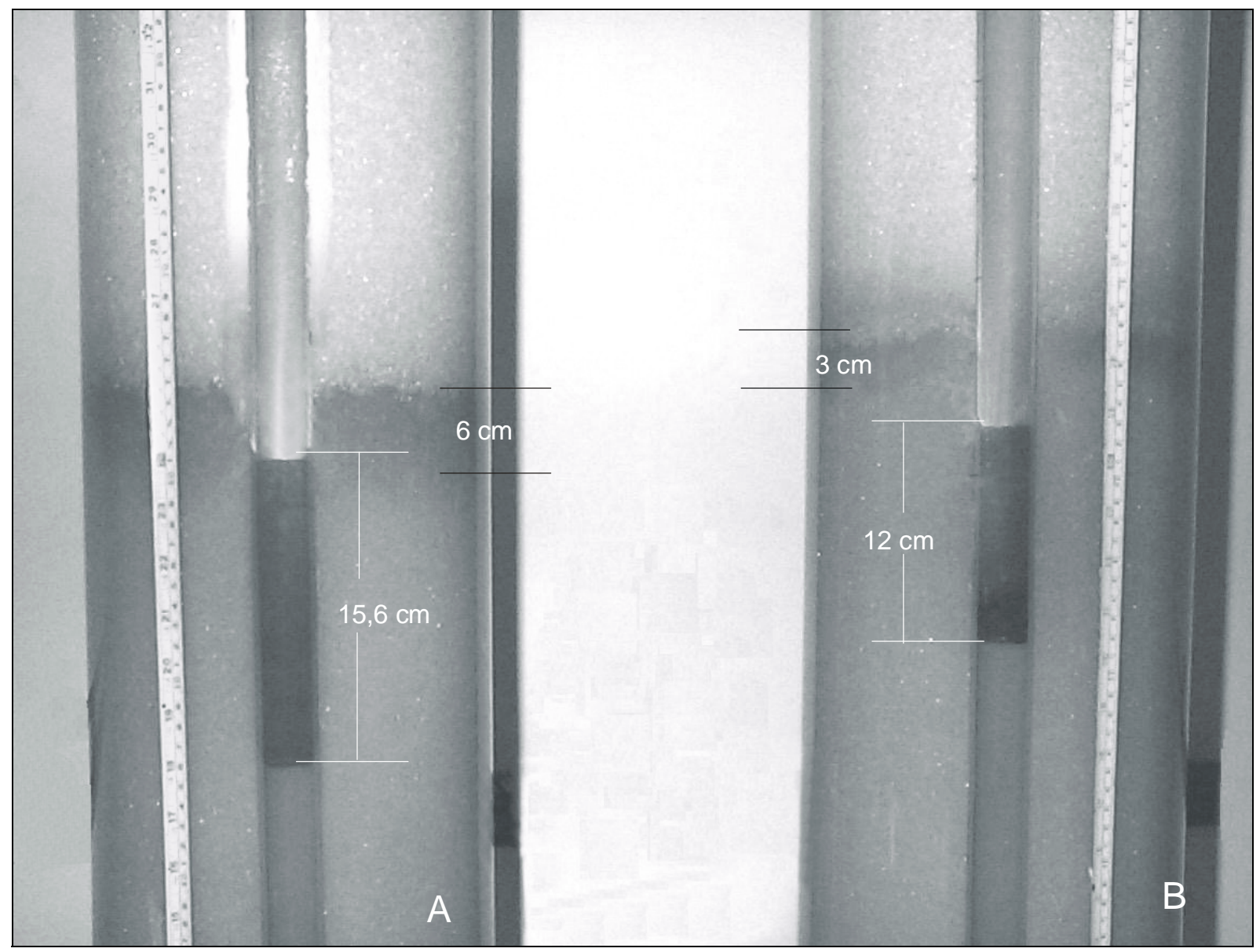

Figura 6- Configuração final do experimento, A gasolina pura e B E24

Figure 6- Experiment setup: A) pure gasoline and B) E24

Isto indica que o projeto de remediação para o E24 baseado na relação com a gasolina pura poderia superestimar o volume de produto a ser extraído do aquífero a $20 \%$.

Além disso, o experimento demonstra que a migração de E24 para o poço de monitoramento ocorre mais rápido que para gasolina comum; o
E24 alcançou a parede da coluna (limite físico da simulação de aquífero) em menos tempo que a gasolina pura.

Em analogia a derramamentos em subsuperfície, a mistura etanol e gasolina forma pluma de hidrocarbonetos em fase dissolvida mais extensa e de mais rápida que a gasolina 
pura. Para detecções em campo, o poço de monitoramento é ferramenta de identificação mediante localizações estratégicas na pluma, principalmente nos limites físicos das áreas contaminadas.

\section{CONCLUSÕES}

A simulação, em laboratório, de um vazamento de gasolina pura e E24 em aqüíferos ideais permitiu as constatações visuais quanto:

- A elevação da franja capilar foi menor para o E24 comparando-se à gasolina pura, como esperado devido ao efeito co-solvente do etanol sobre a tensão interfacial;

- Para a mesma taxa de injeção, o E24 fase livre em menor tempo que a gasolina pura. Isto indica que durante o derrame de E24, o produto livre mover-se-ia a maiores distancias quando comparada à gasolina pura;

- A migração do E24 para o poço foi mais rápida, indicando que um derramamento em subsuperfície poderia ser detectado por poços de monitoramento instalados nas áreas limites da região contaminada;

- Menor quantidade de E24 permanece no aqüífero como fase livre quando comparado à gasolina pura;

- A relação entre espessuras do produto em fase livre dentro do poço para espessura no aquífero do E24 foi de 4 vezes e para gasolina 2,6. Isto indica que o projeto de remediação para E24, com base na relação com a gasolina pura, poderia superestimar o cálculo do volume de combustível a ser recuperado do aqüífero em $20 \%$. 


\section{REFERÊNCIAS}

ADAMSKI, M.; KREMESEC, V.; KOLHATKAR, R.; PEARSON, C.; ROWAN, B., 2005, LNAPL in Fine-Grained Soils: Conceptualization of Saturation, Distribution, Recovery and Their Modeling, Ground Water Monitoring; Remediation 25, no 1/ Winter, pp 100-112.

ABDUL, S.A.; KIA, S.F.; GIBSON, T.L., 1989, Limitations of Monitoring Wells for the Detection and Qualification of Petroleum Products in Soils Aquifers, Ground Water Monitoring Research, Spring, pp 9099.

BEAR, J., 1979, Dynamics of Fluids in Porous Media, Dover Publications, Inc., New York, 764 p.

CAIN, R.B., JOHNSON, J.R., MCCRAY, J.E., BLANFORD, W.J., BRUSSEAU, M.L., 2000, Partitioning Tracer Test for Evaluating Remediation Performance, Ground Water, vol. 38 no 5, Sept-Oct pp 752-761.

DAKIN, R.A.; HOLMES A.T.E TIPLADY, D.J., 1992. Practical aspects of hydrogeology studies for hydrocarbon migration in British Columbia, Subsurface contamination by immiscible fluids, K. U. Weyer editor, Proceedings of the international conference on subsurface contamination by immiscible fluids / Calgary / Canada / 18-20 abril 1990.

OLIVEIRA, E DE, 1997, Ethanol flushing of gasoline residuals - microscale and field scale experiments, Phd of Earth Science, University of Waterloo, Canada.
PASTROVISH, T.L DE, BARADAT, Y., BARTHEL, R., CHIARELLI, A., FUSSELL, D.R., 1979, Protection of Groundwater from Oil Pollution, CONCAWE, Report 3/79, Den Haag, Netherlands.

LAL, R.; BRIDGE, B.J. AND COLLIS-GEORGE, N., 1970, The Effect of Column Diameter on the Infiltration Behaviour of a Swelling Soil, Aust. J. Soil Res., 8, 185-193.

MCDOWELL, C.J; BUSCHECK, T. AND POWERS, S.E., 2003, Behavior of Gasoline Pools Following a Denatured Ethanol Spill, Ground Water, vol. 41, no. 6, novembro-dezembro2003, pp 746-757.

MARINELLI, F.; DURNFORD, D.S., 1996, LNAPL thickness in monitoring wells considering hysteresis and entrapment, Ground Water, vol. 34, no. 3, 405414.

MUSTAFA, M.A. AND LIAO, B., 2000, LNAPL Thickness Interpretation Based on Bail-Down Tests, Ground Water, vol. 38, no. 5, September-October, pp 696-701

SCHIEGG, H.O.E MCBRIDE, J.F., 1987, Laboratory setup to study two-dimensional multiphase flow in porous media, In Proceedings of Petroleum Hydrocarbons and Organic Chemicals in Ground Water Conference, Houston, Texas, p. 371-385. 